\title{
Role of Insulin Resistance in Endothelial Dysfunction
}

\author{
Ranganath Muniyappa, MD, $\mathrm{PhD}^{1}$ and James R. Sowers, $\mathrm{MD}^{2,{ }^{*}}$
}

${ }^{1}$ Clinical Endocrine Section, Diabetes, Endocrinology, and Obesity Branch, National Institute of Diabetes and Digestive and Kidney Diseases, National Institutes of Health, Bethesda, Maryland ${ }^{2}$ Departments of Internal Medicine and Medical Pharmacology and Physiology, University of Missouri School of Medicine, Columbia, Missouri; and Harry S. Truman Memorial Veterans' Hospital, Columbia, Missouri

\begin{abstract}
Insulin resistance is frequently associated with endothelial dysfunction and has been proposed to play a major role in cardiovascular diseases. Insulin exerts pro- and anti-atherogenic actions on the vasculature. The balance between nitric oxide (NO)-dependent vasodilator actions and endothelin-1- dependent vasoconstrictor actions of insulin is regulated by phosphatidylinositol 3kinase-dependent (PI3K) - and mitogen-activated protein kinase (MAPK)-dependent signaling in vascular endothelium, respectively. During insulin-resistant conditions, pathway-specific impairment in PI3K-dependent signaling may cause imbalance between production of NO and secretion of endothelin-1 and lead to endothelial dysfunction. Insulin sensitizers that target pathway-selective impairment in insulin signaling are known to improve endothelial dysfunction. In this review, we discuss the cellular mechanisms in the endothelium underlying vascular actions of insulin, the role of insulin resistance in mediating endothelial dysfunction, and the effect of insulin sensitizers in restoring the balance in pro- and anti-atherogenic actions of insulin.
\end{abstract}

\section{Keywords}

Nitric Oxide; Insulin Resistance; Endothelial Dysfunction; Metabolic Syndrome

\section{Introduction}

Insulin resistance plays a patho-physiological role in type 2 diabetes and is frequently present in obesity, hypertension, coronary artery disease, dyslipidemias, and metabolic syndrome [1,2]. Global epidemic of obesity is driving the increased incidence and prevalence of insulin resistance and its cardiovascular complications [3]. Insulin regulates glucose homeostasis not only by promoting glucose disposal in skeletal muscle and adipose tissue and inhibiting gluconeogenesis in liver [2], but also by regulating nutrient delivery to target tissues by actions on microvasculature [4]. Insulin-induced nitric oxide (NO) production from vascular endothelium leads to increased blood flow that further enhances glucose uptake in skeletal muscle [5].

At the cellular level, balance between phosphatidylinositol 3-kinase- (PI3K)-dependent insulin-signaling pathways that regulate endothelial NO production and mitogen activated protein kinase (MAPK)-dependent insulin-signaling pathways regulating the secretion of the

"Corresponding author for proof and reprints: James R. Sowers, MD, Department of Internal Medicine, University of Missouri School of Medicine, One Hospital Drive, Columbia, Missouri, MO 65212, sowersj@ health.missouri.edu. 
vasoconstrictor endothelin-1 (ET-1) determines the vascular response to insulin. Insulin resistance is typically defined as decreased sensitivity or responsiveness to metabolic actions of insulin such as insulin-mediated glucose disposal. However, diminished sensitivity to the vascular actions of insulin also plays an important role in the pathophysiology of insulinresistant states [6,7]. Indeed, endothelial insulin resistance is typically accompanied by reduced PI3K-NO pathway and an intact or heightened MAPK-ET-1 pathway. Insulin resistant states are associated with metabolic abnormalities that include glucotoxicity, lipotoxicity, and inflammation that also lead to endothelial dysfunction. Indeed, pathwayspecific impairment in PI3K-dependent insulin signaling contributes to reciprocal relationships between insulin resistance and endothelial dysfunction that foster the clustering of metabolic and cardiovascular diseases in insulin-resistant states [8]. Herein, we discuss the role of insulin resistance in endothelial dysfunction and therapeutic interventions that may simultaneously improve both metabolic and endothelial function in insulin-resistant conditions.

\section{Endothelial Dysfunction}

The term "endothelial dysfunction" refers to a maladapted endothelial phenotype characterized by reduced NO bioavailability, increased oxidative stress, elevated expression of pro-inflammatory and pro-thrombotic factors, and abnormal vasoreactivity [9]. Healthy endothelium plays a central role in homeostatic functions by actively secreting various molecules that act in a paracrine, autocrine, and endocrine fashion. These molecules affect vascular tone, endothelial and vascular smooth muscle (VSMC) growth and proliferation, endothelial-leukocyte interactions, platelet adhesion, coagulation, inflammation, and permeability. Vascular tone is modulated by endothelium-derived vasoactive substances that include vasodilators (e.g., $\mathrm{NO}$, prostaglandins $\left(\mathrm{PGI}_{2}\right)$, endothelium-derived hyperpolarization factor (EDHF), epoxyeicosatrienoic acids (EETs)) and vasoconstrictors (e.g., Angiotensin II (Ang II), ET-1, prostanoids, isoprostanes). In addition to affecting vascular tone, key vasodilators such as NO and prostacyclin are anti-proliferative and antiinflammatory, while vasoconstrictors such as ET-1 and Ang II are mitogenic and proinflammatory. Both in the macro- and micro-vasculature (arterioles, capillaries and venules that are less than $150 \mu \mathrm{m}$ in diameter), the balance in actions of vasodilators and vasoconstrictors determine vascular tone and endothelial function.

NO, an important determinant of endothelial function, is produced in vascular endothelium by activation of endothelial NO synthase (eNOS) [10]. Vasodilatory actions of NO are primarily mediated via reductions in VSMC intracellular calcium $\mathrm{Ca}^{2+}$ concentrations secondary to NO-mediated guanylate cyclase activation and cGMP formation. Elevations in endothelial cytoplasmic $\mathrm{Ca}^{2+}$ secondary to the activation of serpentine $\mathrm{G}$ protein-coupled receptors (e.g. acetylcholine receptor) promote binding of calmodulin to and subsequent activation of eNOS. In addition, phosphorylation of eNOS at $\operatorname{Ser}^{1177}$ by serine kinases including Akt, AMPK, and PKA also stimulate production of $\mathrm{NO}$ in a $\mathrm{Ca}^{2+}$-independent manner. Availability of L-arginine (substrate for eNOS) and enzymatic cofactors (NADPH, flavin adenine dinucleotide [FAD], flavinmononucleotide [FMN], and tetrahydrobiopterin $\left.\left[\mathrm{BH}_{4}\right]\right)$ also play a role in regulating NO production by eNOS [11]. In addition to decreasing vascular tone, NO decreases expression of vascular cell adhesion molecules, attenuates production of pro-inflammatory cytokines, decreases leukocyte recruitment, inhibits VSMC proliferation, opposes apoptosis, attenuates platelet aggregation, and reduces monocyte adhesion to the vascular wall [12]. Thus, reductions in NO bioavailability favor a dysfunctional vascular phenotype. Due to the systemic nature of the dysfunction, the manifestations of endothelial dysfunction vary depending on the nature of the vascular bed. 
A dysfunctional endothelium is a harbinger of atherosclerosis and can also contribute to cardiovascular events. Importantly, endothelial dysfunction is independently associated with and predicts cardiac death, myocardial infarction, and stroke [13]. Interestingly, endothelial dysfunction is also linked to insulin-resistant states including diabetes, obesity, and the metabolic syndrome [14]. This increases the susceptibility of patients with these metabolic diseases to cardiovascular complications including accelerated atherosclerosis, coronary heart disease, and hypertension.

\section{Assessment of Endothelial Function}

Studies designed to evaluate endothelial function in humans often assess NO-dependent vasodilation. Measurement of the changes in coronary artery diameter and blood flow in response to intra-coronary infusion of acetylcholine is regarded as the "gold standard" technique. Changes in limb blood flow (assessed by plethysmography) or conduit artery diameter (assessed by ultrasound) in response to intra-arterial infusion of agents that stimulate endothelium-dependent production of NO such as acetylcholine are used primarily in research settings to evaluate endothelial function [9]. Another less-invasive method involves shear stress-induced flow-mediated dilatation (FMD) of the brachial artery. High resolution doppler ultrasonography is used to measure changes in arterial diameter and blood flow in the brachial artery in response to shear stress induced by inflating and deflating a blood pressure cuff (reactive hyperemia). Using this same principle, peripheral endothelial function is measured by finger plethysmography. Increases in digital pulse amplitude after reactive hyperemia are recorded by peripheral arterial tonometry (EndoPAT) [15]. Endothelial function measured using this technique correlates well with coronary endothelial-mediated vasodilatory response to acetylcholine [16]. Currently, limited resolution of current imaging techniques precludes robust assessment of microvascular endothelial function in humans. Nevertheless, positron emission tomography (PET) [17], contrast-imaging with microbubbles [18], and laser-doppler perfusion [19] monitoring have been used to monitor changes in capillary blood flow in various vascular beds in response to agents/interventions known to augment endothelial-mediated blood flow.

Elevated circulating plasma concentrations of biomarkers for inflammation, hemostasis, and oxidative stress are also used as indicators that accompany and promote endothelial dysfunction [9]. Among them circulating levels of P- and E-selectin, soluble inter-cellular adhesion molecules (sICAM-1), soluble vascular cell adhesion molecule (sVCAM), oxidized low-density lipoprotein (oxLDL), plasminogen activator inhibitor-1 (PAI-1), and asymmetrical dimethylarginine (ADMA) have been used as a marker of endothelial dysfunction.

\section{Selective Resistance to Insulin Actions in the Endothelium}

Insulin resistant states are characterized by attenuation of some cell-specific insulin responses, while other actions of insulin not only persist but may be exaggerated. This selective insulin resistance is observed in the liver where insulin-mediated suppression of glucose production is impaired but not lipogenesis [20]. Similarly, in the endothelium, insulin-stimulated NO, but not ET-1 production is impaired [21]. This selective insulin resistance is explained by the pathway-specific impairment in insulin signaling pathways (Fig. 1). Insulin-signaling pathways regulating endothelial NO and ET-1 production have been elucidated [4,22]. Detailed description of these pathways is described elsewhere in this issue but briefly, insulin binding to its receptor results in phosphorylation of IRS-1 which then binds and activates PI3K. PI-3,4,5-triphosphate $\left(\mathrm{PIP}_{3}\right)$, a product of PI3K activity, stimulates phosphorylation and activation of PDK-1 that in turn phosphorylates and activates Akt. Akt directly phosphorylates eNOS at Ser ${ }^{1177}$ resulting in increased eNOS 
activity and subsequent NO production. Insulin stimulates ET-1 production using MAPKdependent (but not PI3K-dependent) signaling pathways [23]. Insulin stimulates increased expression of PAI-1, VCAM-1 and E-selectin on endothelium using MAPK-dependent pathway [24,25]. Inhibition of PI3K or Akt increases insulin-induced PAI-1 and expression of adhesion molecules [24]. These findings suggest that insulin-stimulated PI3K/Akt pathways oppose atherothrombotic factors in endothelium by multiple mechanisms including production of beneficial molecules such as $\mathrm{NO}$ and inhibition of pathogenic molecules including PAI-1, ICAM-1, VCAM-1, and E-selectin. In the setting of selective impairment of PI3K activation and compensatory hyperinsulinemia, the pro-hypertensive, atherogenic, thrombogenic, and pro-coagulant actions of insulin dominates to lead to endothelial dysfunction.

\section{Selective Insulin Resistance in Animal Models}

Selective insulin resistance has been observed in various rodent models of global insulin resistance $[26,23]$. Using genetic approaches, various groups have examined the role of endothelium-specific insulin resistance in vascular dysfunction [27-30]. Mice lacking insulin receptors specifically in vascular endothelium (VENIRKO) have normal glucose metabolism and blood pressure, but reduced expression of eNOS and ET-1 in endothelium [27]. However, when challenged with high-salt diet, VENIRKO mice develop insulin resistance and elevated blood pressure [27]. Similarly, mice expressing endothelium-specific expression of a dominant negative mutant human insulin receptor develop endothelial dysfunction. This was evident by impaired NO release to insulin, acetylcholine, or a calcium ionophore. Furthermore, there was an increase in the expression of NADPH oxidase that leads to oxidative stress and reduced NO bioavailability [28]. In the vasculature of heterozygous global insulin receptor knockout mice (IRKO) with metabolic insulin resistance, insulin-stimulated phosphorylation and activation of eNOS is impaired resulting in reduced basal and insulin-stimulated NO release [29]. Likewise, IRS-1 (IRS-1 ${ }^{-/-}$) and IRS-2 (IRS-2 ${ }^{-/}$) deficient mice not only exhibit resistance to the metabolic actions of insulin, but also demonstrate diminished endothelial NO activity [30]. These findings suggest that complex interactions between insulin action, eNOS, ET-1, and oxidative stress affect the metabolic and vascular phenotype in these mice. In addition, in these models, the proximal nodes in insulin signaling (IR and IRS-1) are affected thereby affecting both the PI3K and MAPK pathways. Perhaps this explains the relatively mild endothelial dysfunction observed in these rodent models.

In contrast to previously mentioned rodent models, endothelial dysfunction is pronounced in rodents that exhibit selective-impairment in insulin resistance. Genetic ablation of Akt1 in high fat-fed $\mathrm{ApoE}^{-/-}$mice leads to increased atherogenesis and endothelial dysfunction [31]. Obese Zucker rats demonstrate pathway selective insulin resistance in PI3K-dependent signaling (with intact MAPK signaling) in the vasculature [26]. This results in impaired NOmediated vasodilation and augmented ET-1-mediated vasoconstriction in response to insulin. In spontaneously hypertensive rats (SHRs) NO-dependent vasodilator response to insulin is significantly impaired. However, inhibiting MAPK-dependent pathways unmasks vasodilator actions of insulin [23]. Treatment of micro-vessels with ET-1 receptor antagonists, BQ788 and BQ123 also improves insulin-mediated vasodilation in these rats. These findings suggest that selective impairment in PI3K- pathways leads to decreased endothelial production of $\mathrm{NO}$ while increased insulin signaling through MAPK-dependent pathways leads to elevated secretion of ET-1. Thus, partial and selective defects in insulin signaling or NO activity are sufficient to cause endothelial dysfunction during nutritional stress, inflammation, and dysmetabolic states. 


\section{Insights about Selective Insulin Resistance in Human Studies}

Studies in patients with extremely rare mutations in either insulin receptor or Akt2 genes support the concept of selective insulin resistance in the liver [20]. Patients with IR mutations manifest a loss of suppression of hepatic glucose output without enhanced hepatic lipogenesis [20]. However, increased de novo lipogenesis and hepatic glucogenesis are observed in patients with Akt2 mutations. These results suggest that selective insulin resistance in the PI3K-Akt pathway uncouples gluconeogenesis and lipogenesis. Endothelial function has not been studied in these patients. Nevertheless, findings from other studies support the notion of pathway-selective insulin resistance in the human endothelium. Subjects with IRS-1 polymorphism (glycine to arginine at codon 972), are not only insulinresistant, but also have endothelial dysfunction [32]. In endothelial cells from subjects carrying the G972R-IRS-1 variant, insulin-mediated PI3-K/Akt/eNOS activation is diminished [33]. Similarly, activation of Akt is impaired in internal mammary arteries obtained from patients with diabetes when compared with non-diabetics [34]. In addition, the absolute levels of phospho-eNOS (Ser1177) are also decreased in vascular tissue from diabetic patients [34]. These findings suggest that impaired endothelial insulin signaling and reduced NO activity contributes to endothelial dysfunction in insulin resistant states.

As previously discussed, pathway-specific insulin resistance results in enhanced effects of insulin to stimulate ET-1 production and promote increased vasoconstrictor tone. Coronary vessels with vulnerable and obstructive atherosclerosis are characterized by an increase in ET-1 activity and endothelial dysfunction [35]. The parallel increase in ET-1 activity and diminished NO bioactivity contributes to abnormal vascular function. Human studies in overweight [36], obese [37], hypertensive [38,39] and diabetic [40,37] subjects support this notion. Vascular $\mathrm{ET}_{\mathrm{A}} / \mathrm{ET}_{\mathrm{B}}$ receptor blockade in the forearm significantly increases endothelium-dependent vasodilatation in overweight, insulin-resistant subjects but not in lean, healthy controls $[36,38]$. Similarly, selective $\mathrm{ET}_{\mathrm{A}}$ receptor blockade in the forearm significantly increases forearm blood flow in patients with type 2 diabetes [40]. Hyperinsulinemia stimulates ET-1 secretion [41] and accentuated ET-1 activity may cause insulin resistance [42]. Thus, human studies support the idea that increased endogenous activity of ET-1 and reduced is a feature of endothelial dysfunction in insulin resistance, obesity, hypertension, and diabetes mellitus. This phenotype is a manifestation of pathwayselective insulin resistance in the endothelium.

\section{Relationship between Insulin Resistance and Endothelial Dysfunction: A Meta-analysis}

Many cross-sectional studies have examined the relationship between insulin resistance/ sensitivity and endothelial function [43-47] [48] [49-51,7,52-54] [55,56]. In these studies, endothelial function was evaluated by high resolution brachial artery ultrasound, venous occlusion plethysmography, and laser doppler imaging techniques. Insulin sensitivity was assessed by euglycemic hyperinsulinemic clamps and surrogate indices (HOMA-IR, frequently sampled intravenous glucose tolerance test). In an effort to evaluate the contribution of insulin resistance to endothelial dysfunction, we pooled univariate correlation coefficients from these studies using Schmidt-Hunter model. Figure 2 presents the pooled correlation coefficient for 12 studies $(\mathrm{N}=3190)$ was $0.14(\mathrm{p}=<0.001,95 \%$ CI: $-0.09--0.20)$. These results suggest that the correlation between insulin resistance and endothelial function is rather weak. The test for heterogeneity in the included studies was significant $(\mathrm{p}<0.05)$. Given the heterogeneity of the studies, the different techniques to assess insulin resistance and endothelial function, and the limited number of studies reviewed, it is possible that we are underestimating the strength of this relationship. Nevertheless, in many studies, upon multivariate analysis that included adjustment of other 
potential modulators of endothelial function, insulin resistance was no longer a significant predictor of endothelial dysfunction [46,48-50].

These findings together suggest that insulin resistance may only partly explain the impaired endothelial function. It is also possible that other manifestations of insulin resistance such as hyperglycemia, dyslipidemia, inflammation, and obesity may be intermediary mediators that act in concert with insulin resistance to mediate endothelial dysfunction. The role of glucotoxicity, lipotoxicity, and inflammation in endothelial dysfunction is reviewed in detail elsewhere in this issue. However, hyperglycemia, hyperlipidemia, and various cytokines are known to selectively impair PI3K/Akt/eNOS pathway, increase oxidative stress, and enhance the release of ET-1 from the endothelium (Fig. 1) [4].

\section{Insulin Sensitizers and Endothelial Dysfunction}

Calorie restriction and physical exercise, interventions known to improve insulin sensitivity, also improves endothelial dysfunction [57-69]. Calorie restriction improves NO-dependent vasodilation and simulatenously reduces circulating ET-1 levels in insulin resistant individuals [70-72]. Regular exercise increases vascular eNOS protein expression and activity via PI3K/Akt-dependent phosphorylation in humas [73]. Thus the beneficial effects of these life style modifications may involve enhanced insulin signaling, increased eNOS activity, and reductions in oxidative and inflammatory stress that leads to the rebalancing the vasocontrictor and vasodilator actions of insulin

Metformin, a frequently used insulin sensitizer stimulates adenyl monophosphate kinase (AMP-kinase) that in turn phosphorylates and activates eNOS in endothelial cells in culture [74]. Consequently, administration of metformin not only improves endothelium-dependent vasodilation but simultaneously decreases circulating ET-1 levels in insulin-resistant individuals [75]. Similarly, administration of another insulin sensitizer, rosiglitazone also improves FMD and acetylcholine-mediated vasodilation in individuals with the metabolic syndrome [76]. It is unclear whether improvement in insulin sensitivity per se was the proximal mediator of improved endothelial function in these studies. However, metformin has been shown to significantly reduce CV events in patients with insulin resistance [77]. Considering that prevention of insulin resistance is predicted to reduce myocardial infarctions by $42 \%$ [78], therapies aimed at improving insulin sensitivity may offer a more rational choice in treating endothelial dysfunction in dysmetabolic states.

\section{Summary}

Endothelium specific selective impairment of PI3K-dependent insulin signaling pathways favors the phenotype of endothelial dysfunction and insulin resistance. Targeting this selective impairment has the potential to simultaneously ameliorate endothelial dysfunction and insulin resistance. Future studies in patients with genetic mutations in insulin receptor, Akt, or PTEN, may offer additional insights aimed at delineating the role of insulin resistance in endothelial dysfunction. In the meantime however, insulin sensitization therapy over insulin provision should be considered in insulin-resistant subjects to improve endothelial health and reduce cardiovascular disease.

\section{Acknowledgments}

This work was supported by the Intramural Research Program of National Institute of Diabetes and Digestive and Kidney Diseases, National Institutes of Health (NIH). The research of J.R.S. is supported by NIH (R01 HL73101-08 and R01 HL107910-03) and Veterans Affairs Merit System 0018. 


\section{References}

1. DeFronzo RA, Ferrannini E. Insulin resistance. A multifaceted syndrome responsible for NIDDM, obesity, hypertension, dyslipidemia, and atherosclerotic cardiovascular disease. Diabetes Care. 1991; 14(3):173-194. [PubMed: 2044434]

2. Petersen KF, Dufour S, Savage DB, Bilz S, Solomon G, Yonemitsu S, et al. The role of skeletal muscle insulin resistance in the pathogenesis of the metabolic syndrome. Proc Natl Acad Sci U S A. 2007; 104(31):12587-12594. [PubMed: 17640906]

3. Poirier P, Giles TD, Bray GA, Hong Y, Stern JS, Pi-Sunyer FX, et al. Obesity and cardiovascular disease: pathophysiology, evaluation, and effect of weight loss: an update of the 1997 American Heart Association Scientific Statement on Obesity and Heart Disease from the Obesity Committee of the Council on Nutrition, Physical Activity, and Metabolism. Circulation. 2006; 113(6):898-918. [PubMed: 16380542]

4. Muniyappa R, Montagnani M, Koh KK, Quon MJ. Cardiovascular actions of insulin. Endocr Rev. 2007; 28(5):463-491. [PubMed: 17525361]

5. Vincent MA, Clerk LH, Lindner JR, Klibanov AL, Clark MG, Rattigan S, et al. Microvascular recruitment is an early insulin effect that regulates skeletal muscle glucose uptake in vivo. Diabetes. 2004; 53(6):1418-1423. [PubMed: 15161743]

6. Baron AD, Laakso M, Brechtel G, Edelman SV. Mechanism of insulin resistance in insulindependent diabetes mellitus: a major role for reduced skeletal muscle blood flow. J Clin Endocrinol Metab. 1991; 73(3):637-643. [PubMed: 1874938]

7. Natali A, Taddei S, Quinones Galvan A, Camastra S, Baldi S, Frascerra S, et al. Insulin sensitivity, vascular reactivity, and clamp-induced vasodilatation in essential hypertension. Circulation. 1997; 96(3):849-855. [PubMed: 9264492]

8. Kim JA, Montagnani M, Koh KK, Quon MJ. Reciprocal relationships between insulin resistance and endothelial dysfunction: molecular and pathophysiological mechanisms. Circulation. 2006; 113(15):1888-1904. [PubMed: 16618833]

9. Barac A, Campia U, Panza JA. Methods for evaluating endothelial function in humans. Hypertension. 2007; 49(4):748-760. [PubMed: 17309954]

10. Zeng G, Quon MJ. Insulin-stimulated production of nitric oxide is inhibited by wortmannin. Direct measurement in vascular endothelial cells. J Clin Invest. 1996; 98(4):894-898. [PubMed: 8770859]

11. Dudzinski DM, Michel T. Life history of eNOS: partners and pathways. Cardiovasc Res. 2007; 75(2):247-260. [PubMed: 17466957]

12. Herman AG, Moncada S. Therapeutic potential of nitric oxide donors in the prevention and treatment of atherosclerosis. Eur Heart J. 2005; 26(19):1945-1955. [PubMed: 15911567]

13. Bonetti PO, Lerman LO, Lerman A. Endothelial dysfunction: a marker of atherosclerotic risk. Arterioscler Thromb Vasc Biol. 2003; 23(2):168-175. [PubMed: 12588755]

14. Muris DM, Houben AJ, Schram MT, Stehouwer CD. Microvascular Dysfunction Is Associated With a Higher Incidence of Type 2 Diabetes Mellitus--Brief Report: A Systematic Review and Meta-Analysis. Arterioscler Thromb Vasc Biol. 2012

15. Hamburg NM, Keyes MJ, Larson MG, Vasan RS, Schnabel R, Pryde MM, et al. Cross-sectional relations of digital vascular function to cardiovascular risk factors in the Framingham Heart Study. Circulation. 2008; 117(19):2467-2474. [PubMed: 18458169]

16. Bonetti PO, Pumper GM, Higano ST, Holmes DR Jr, Kuvin JT, Lerman A. Noninvasive identification of patients with early coronary atherosclerosis by assessment of digital reactive hyperemia. J Am Coll Cardiol. 2004; 44(11):2137-2141. [PubMed: 15582310]

17. Prior JO, Quinones MJ, Hernandez-Pampaloni M, Facta AD, Schindler TH, Sayre JW, et al. Coronary circulatory dysfunction in insulin resistance, impaired glucose tolerance, and type 2 diabetes mellitus. Circulation. 2005; 111(18):2291-2298. [PubMed: 15851590]

18. Muniyappa R, Hall G, Kolodziej TL, Karne RJ, Crandon SK, Quon MJ. Cocoa consumption for 2 wk enhances insulin-mediated vasodilatation without improving blood pressure or insulin resistance in essential hypertension. Am J Clin Nutr. 2008; 88(6):1685-1696. [PubMed: 19064532] 
19. Ketel IJ, Stehouwer CD, Serne EH, Korsen TJ, Hompes PG, Smulders YM, et al. Obese but not normal-weight women with polycystic ovary syndrome are characterized by metabolic and microvascular insulin resistance. J Clin Endocrinol Metab. 2008; 93(9):3365-3372. [PubMed: 18593766]

20. Semple RK, Sleigh A, Murgatroyd PR, Adams CA, Bluck L, Jackson S, et al. Postreceptor insulin resistance contributes to human dyslipidemia and hepatic steatosis. J Clin Invest. 2009; 119(2): 315-322. [PubMed: 19164855]

21. Lteif A, Vaishnava P, Baron AD, Mather KJ. Endothelin limits insulin action in obese/insulinresistant humans. Diabetes. 2007; 56(3):728-734. [PubMed: 17327443]

22. Vincent MA, Montagnani M, Quon MJ. Molecular and physiologic actions of insulin related to production of nitric oxide in vascular endothelium. Curr Diab Rep. 2003; 3(4):279-288. [PubMed: 12866989]

23. Potenza MA, Marasciulo FL, Chieppa DM, Brigiani GS, Formoso G, Quon MJ, et al. Insulin resistance in spontaneously hypertensive rats is associated with endothelial dysfunction characterized by imbalance between NO and ET-1 production. Am J Physiol Heart Circ Physiol. 2005; 289(2):H813-H822. [PubMed: 15792994]

24. Montagnani M, Golovchenko I, Kim I, Koh GY, Goalstone ML, Mundhekar AN, et al. Inhibition of phosphatidylinositol 3-kinase enhances mitogenic actions of insulin in endothelial cells. J Biol Chem. 2002; 277(3):1794-1799. [PubMed: 11707433]

25. Mukai Y, Wang CY, Rikitake Y, Liao JK. Phosphatidylinositol 3-kinase/protein kinase Akt negatively regulates plasminogen activator inhibitor type 1 expression in vascular endothelial cells. Am J Physiol Heart Circ Physiol. 2007; 292(4):H1937-H1942. [PubMed: 17172275]

26. Jiang ZY, Lin YW, Clemont A, Feener EP, Hein KD, Igarashi M, et al. Characterization of selective resistance to insulin signaling in the vasculature of obese Zucker (fa/fa) rats. J Clin Invest. 1999; 104(4):447-457. [PubMed: 10449437]

27. Vicent D, Ilany J, Kondo T, Naruse K, Fisher SJ, Kisanuki YY, et al. The role of endothelial insulin signaling in the regulation of vascular tone and insulin resistance. J Clin Invest. 2003; 111(9):1373-1380. [PubMed: 12727929]

28. Duncan ER, Crossey PA, Walker S, Anilkumar N, Poston L, Douglas G, et al. Effect of endothelium-specific insulin resistance on endothelial function in vivo. Diabetes. 2008; 57(12): 3307-3314. [PubMed: 18835939]

29. Wheatcroft SB, Shah AM, Li JM, Duncan E, Noronha BT, Crossey PA, et al. Preserved glucoregulation but attenuation of the vascular actions of insulin in mice heterozygous for knockout of the insulin receptor. Diabetes. 2004; 53(10):2645-2652. [PubMed: 15448096]

30. Kubota T, Kubota N, Moroi M, Terauchi Y, Kobayashi T, Kamata K, et al. Lack of insulin receptor substrate-2 causes progressive neointima formation in response to vessel injury. Circulation. 2003; 107(24):3073-3080. [PubMed: 12810606]

31. Fernandez-Hernando C, Ackah E, Yu J, Suarez Y, Murata T, Iwakiri Y, et al. Loss of Akt1 leads to severe atherosclerosis and occlusive coronary artery disease. Cell Metab. 2007; 6(6):446-457. [PubMed: 18054314]

32. Perticone F, Sciacqua A, Scozzafava A, Ventura G, Laratta E, Pujia A, et al. Impaired endothelial function in never-treated hypertensive subjects carrying the Arg972 polymorphism in the insulin receptor substrate-1 gene. J Clin Endocrinol Metab. 2004; 89(7):3606-3609. [PubMed: 15240653]

33. Federici M, Pandolfi A, De Filippis EA, Pellegrini G, Menghini R, Lauro D, et al. G972R IRS-1 variant impairs insulin regulation of endothelial nitric oxide synthase in cultured human endothelial cells. Circulation. 2004; 109(3):399-405. [PubMed: 14707024]

34. Okon EB, Chung AW, Rauniyar P, Padilla E, Tejerina T, McManus BM, et al. Compromised arterial function in human type 2 diabetic patients. Diabetes. 2005; 54(8):2415-2423. [PubMed: 16046309]

35. Lerman A, Edwards BS, Hallett JW, Heublein DM, Sandberg SM, Burnett JC Jr. Circulating and tissue endothelin immunoreactivity in advanced atherosclerosis. N Engl J Med. 1991; 325(14): 997-1001. [PubMed: 1886637] 
36. Shemyakin A, Bohm F, Wagner H, Efendic S, Bavenholm P, Pernow J. Enhanced endotheliumdependent vasodilatation by dual endothelin receptor blockade in individuals with insulin resistance. J Cardiovasc Pharmacol. 2006; 47(3):385-390. [PubMed: 16633080]

37. Mather KJ, Mirzamohammadi B, Lteif A, Steinberg HO, Baron AD. Endothelin contributes to basal vascular tone and endothelial dysfunction in human obesity and type 2 diabetes. Diabetes. 2002; 51(12):3517-3523. [PubMed: 12453909]

38. Cardillo C, Campia U, Kilcoyne CM, Bryant MB, Panza JA. Improved endothelium-dependent vasodilation after blockade of endothelin receptors in patients with essential hypertension. Circulation. 2002; 105(4):452-456. [PubMed: 11815427]

39. Cardillo C, Campia U, Iantorno M, Panza JA. Enhanced vascular activity of endogenous endothelin-1 in obese hypertensive patients. Hypertension. 2004; 43(1):36-40. [PubMed: 14656951]

40. Cardillo C, Campia U, Bryant MB, Panza JA. Increased activity of endogenous endothelin in patients with type II diabetes mellitus. Circulation. 2002; 106(14):1783-1787. [PubMed: 12356630]

41. Cardillo C, Nambi SS, Kilcoyne CM, Choucair WK, Katz A, Quon MJ, et al. Insulin stimulates both endothelin and nitric oxide activity in the human forearm. Circulation. 1999; 100(8):820-825. [PubMed: 10458717]

42. Ahlborg G, Lindstrom J. Insulin sensitivity and big ET-1 conversion to ET-1 after ETA- or ETBreceptor blockade in humans. J Appl Physiol. 2002; 93(6):2112-2121. [PubMed: 12391119]

43. Steinberg HO, Chaker H, Leaming R, Johnson A, Brechtel G, Baron AD. Obesity/insulin resistance is associated with endothelial dysfunction. Implications for the syndrome of insulin resistance. J Clin Invest. 1996; 97(11):2601-2610. [PubMed: 8647954]

44. Balletshofer BM, Rittig K, Enderle MD, Volk A, Maerker E, Jacob S, et al. Endothelial dysfunction is detectable in young normotensive first-degree relatives of subjects with type 2 diabetes in association with insulin resistance. Circulation. 2000; 101(15):1780-1784. [PubMed: 10769277]

45. Han KA, Patel Y, Lteif AA, Chisholm R, Mather KJ. Contributions of dysglycaemia, obesity, and insulin resistance to impaired endothelium-dependent vasodilation in humans. Diabetes Metab Res Rev. 2011; 27(4):354-361. [PubMed: 21309061]

46. Caballero AE, Arora S, Saouaf R, Lim SC, Smakowski P, Park JY, et al. Microvascular and macrovascular reactivity is reduced in subjects at risk for type 2 diabetes. Diabetes. $1999 ; 48(9)$ : 1856-1862. [PubMed: 10480619]

47. Lteif AA, Han K, Mather KJ. Obesity, insulin resistance, and the metabolic syndrome: determinants of endothelial dysfunction in whites and blacks. Circulation. 2005; 112(1):32-38. [PubMed: 15983246]

48. Title LM, Lonn E, Charbonneau F, Fung M, Mather KJ, Verma S, et al. Relationship between brachial artery flow-mediated dilatation, hyperemic shear stress, and the metabolic syndrome. Vasc Med. 2008; 13(4):263-270. [PubMed: 18940902]

49. Lind L. Endothelium-dependent vasodilation, insulin resistance and the metabolic syndrome in an elderly cohort: the Prospective Investigation of the Vasculature in Uppsala Seniors (PIVUS) study. Atherosclerosis. 2008; 196(2):795-802. [PubMed: 17335830]

50. Wendelhag I, Fagerberg B, Hulthe J, Bokemark L, Wikstrand J. Endothelium-dependent flowmediated vasodilatation, insulin resistance and the metabolic syndrome in 60 -year-old men. $\mathrm{J}$ Intern Med. 2002; 252(4):305-313. [PubMed: 12366603]

51. Petrie JR, Ueda S, Webb DJ, Elliott HL, Connell JM. Endothelial nitric oxide production and insulin sensitivity. A physiological link with implications for pathogenesis of cardiovascular disease. Circulation. 1996; 93(7):1331-1333. [PubMed: 8641020]

52. Tack CJ, Ong MK, Lutterman JA, Smits P. Insulin-induced vasodilatation and endothelial function in obesity/insulin resistance. Effects of troglitazone. Diabetologia. 1998; 41(5):569-576. [PubMed: 9628275]

53. Hogikyan RV, Galecki AT, Pitt B, Halter JB, Greene DA, Supiano MA. Specific impairment of endothelium-dependent vasodilation in subjects with type 2 diabetes independent of obesity. J Clin Endocrinol Metab. 1998; 83(6):1946-1952. [PubMed: 9626124] 
54. Jaap AJ, Shore AC, Tooke JE. Relationship of insulin resistance to microvascular dysfunction in subjects with fasting hyperglycaemia. Diabetologia. 1997; 40(2):238-243. [PubMed: 9049487]

55. Watts GF, O'Brien SF, Silvester W, Millar JA. Impaired endothelium-dependent and independent dilatation of forearm resistance arteries in men with diet-treated non-insulin-dependent diabetes: role of dyslipidaemia. Clin Sci (Lond). 1996; 91(5):567-573. [PubMed: 8942395]

56. Williams SB, Cusco JA, Roddy MA, Johnstone MT, Creager MA. Impaired nitric oxide-mediated vasodilation in patients with non-insulin-dependent diabetes mellitus. J Am Coll Cardiol. 1996; 27(3):567-574. [PubMed: 8606266]

57. Sola S, Mir MQ, Cheema FA, Khan-Merchant N, Menon RG, Parthasarathy S, et al. Irbesartan and lipoic acid improve endothelial function and reduce markers of inflammation in the metabolic syndrome: results of the Irbesartan and Lipoic Acid in Endothelial Dysfunction (ISLAND) study. Circulation. 2005; 111(3):343-348. [PubMed: 15655130]

58. Heitzer T, Finckh B, Albers S, Krohn K, Kohlschutter A, Meinertz T. Beneficial effects of alphalipoic acid and ascorbic acid on endothelium-dependent, nitric oxide-mediated vasodilation in diabetic patients: relation to parameters of oxidative stress. Free Radic Biol Med. 2001; 31(1):5361. [PubMed: 11425490]

59. Chen H, Karne RJ, Hall G, Campia U, Panza JA, Cannon RO 3rd, et al. High-dose oral vitamin C partially replenishes vitamin $\mathrm{C}$ levels in patients with Type 2 diabetes and low vitamin $\mathrm{C}$ levels but does not improve endothelial dysfunction or insulin resistance. Am J Physiol Heart Circ Physiol. 2006; 290(1):H137-H145. [PubMed: 16126809]

60. Perticone F, Ceravolo R, Candigliota M, Ventura G, Iacopino S, Sinopoli F, et al. Obesity and body fat distribution induce endothelial dysfunction by oxidative stress: protective effect of vitamin C. Diabetes. 2001; 50(1):159-165. [PubMed: 11147782]

61. Lekakis JP, Anastasiou EA, Papamichael CM, Stamatelopoulos KS, Dagre AG, Alevizaki MC, et al. Short-term oral ascorbic acid improves endothelium-dependent vasodilatation in women with a history of gestational diabetes mellitus. Diabetes Care. 2000; 23(9):1432-1434. [PubMed: 10977048]

62. Darko D, Dornhorst A, Kelly FJ, Ritter JM, Chowienczyk PJ. Lack of effect of oral vitamin C on blood pressure, oxidative stress and endothelial function in Type II diabetes. Clin Sci (Lond). 2002; 103(4):339-344. [PubMed: 12241530]

63. Regensteiner JG, Popylisen S, Bauer TA, Lindenfeld J, Gill E, Smith S, et al. Oral L-arginine and vitamins $\mathrm{E}$ and $\mathrm{C}$ improve endothelial function in women with type 2 diabetes. Vasc Med. 2003; 8(3):169-175. [PubMed: 14989557]

64. Beckman JA, Goldfine AB, Gordon MB, Garrett LA, Keaney JF Jr, Creager MA. Oral antioxidant therapy improves endothelial function in Type 1 but not Type 2 diabetes mellitus. Am J Physiol Heart Circ Physiol. 2003; 285(6):H2392-H2398. [PubMed: 12881209]

65. Pena AS, Wiltshire E, Gent R, Piotto L, Hirte C, Couper J. Folic acid does not improve endothelial function in obese children and adolescents. Diabetes Care. 2007; 30(8):2122-2127. [PubMed: 17519435]

66. Title LM, Ur E, Giddens K, McQueen MJ, Nassar BA. Folic acid improves endothelial dysfunction in type 2 diabetes--an effect independent of homocysteine-lowering. Vasc Med. 2006; 11(2):101109. [PubMed: 16886840]

67. Heitzer T, Krohn K, Albers S, Meinertz T. Tetrahydrobiopterin improves endothelium-dependent vasodilation by increasing nitric oxide activity in patients with Type II diabetes mellitus. Diabetologia. 2000; 43(11):1435-1438. [PubMed: 11126415]

68. Nystrom T, Nygren A, Sjoholm A. Tetrahydrobiopterin increases insulin sensitivity in patients with type 2 diabetes and coronary heart disease. Am J Physiol Endocrinol Metab. 2004; 287(5):E919-E925. [PubMed: 15265759]

69. Grassi D, Necozione S, Lippi C, Croce G, Valeri L, Pasqualetti P, et al. Cocoa reduces blood pressure and insulin resistance and improves endothelium-dependent vasodilation in hypertensives. Hypertension. 2005; 46(2):398-405. [PubMed: 16027246]

70. Hamdy O, Ledbury S, Mullooly C, Jarema C, Porter S, Ovalle K, et al. Lifestyle modification improves endothelial function in obese subjects with the insulin resistance syndrome. Diabetes Care. 2003; 26(7):2119-2125. [PubMed: 12832323] 
71. Maeda S, Jesmin S, Iemitsu M, Otsuki T, Matsuo T, Ohkawara K, et al. Weight loss reduces plasma endothelin-1 concentration in obese men. Exp Biol Med (Maywood). 2006; 231(6):10441047. [PubMed: 16741046]

72. Hotta K, Funahashi T, Arita Y, Takahashi M, Matsuda M, Okamoto Y, et al. Plasma concentrations of a novel, adipose-specific protein, adiponectin, in type 2 diabetic patients. Arterioscler Thromb Vasc Biol. 2000; 20(6):1595-1599. [PubMed: 10845877]

73. Hambrecht R, Adams V, Erbs S, Linke A, Krankel N, Shu Y, et al. Regular physical activity improves endothelial function in patients with coronary artery disease by increasing phosphorylation of endothelial nitric oxide synthase. Circulation. 2003; 107(25):3152-3158. [PubMed: 12810615]

74. Davis BJ, Xie Z, Viollet B, Zou MH. Activation of the AMP-activated kinase by antidiabetes drug metformin stimulates nitric oxide synthesis in vivo by promoting the association of heat shock protein 90 and endothelial nitric oxide synthase. Diabetes. 2006; 55(2):496-505. [PubMed: 16443786]

75. Diamanti-Kandarakis E, Alexandraki K, Protogerou A, Piperi C, Papamichael C, Aessopos A, et al. Metformin administration improves endothelial function in women with polycystic ovary syndrome. Eur J Endocrinol. 2005; 152(5):749-756. [PubMed: 15879361]

76. Natali A, Baldeweg S, Toschi E, Capaldo B, Barbaro D, Gastaldelli A, et al. Vascular effects of improving metabolic control with metformin or rosiglitazone in type 2 diabetes. Diabetes Care. 2004; 27(6):1349-1357. [PubMed: 15161787]

77. UKPDS. Effect of intensive blood-glucose control with metformin on complications in overweight patients with type 2 diabetes (UKPDS 34). UK Prospective Diabetes Study (UKPDS) Group. Lancet. 1998; 352(9131):854-865. [PubMed: 9742977]

78. Eddy D, Schlessinger L, Kahn R, Peskin B, Schiebinger R. Relationship of insulin resistance and related metabolic variables to coronary artery disease: a mathematical analysis. Diabetes Care. 2009; 32(2):361-366. [PubMed: 19017770] 


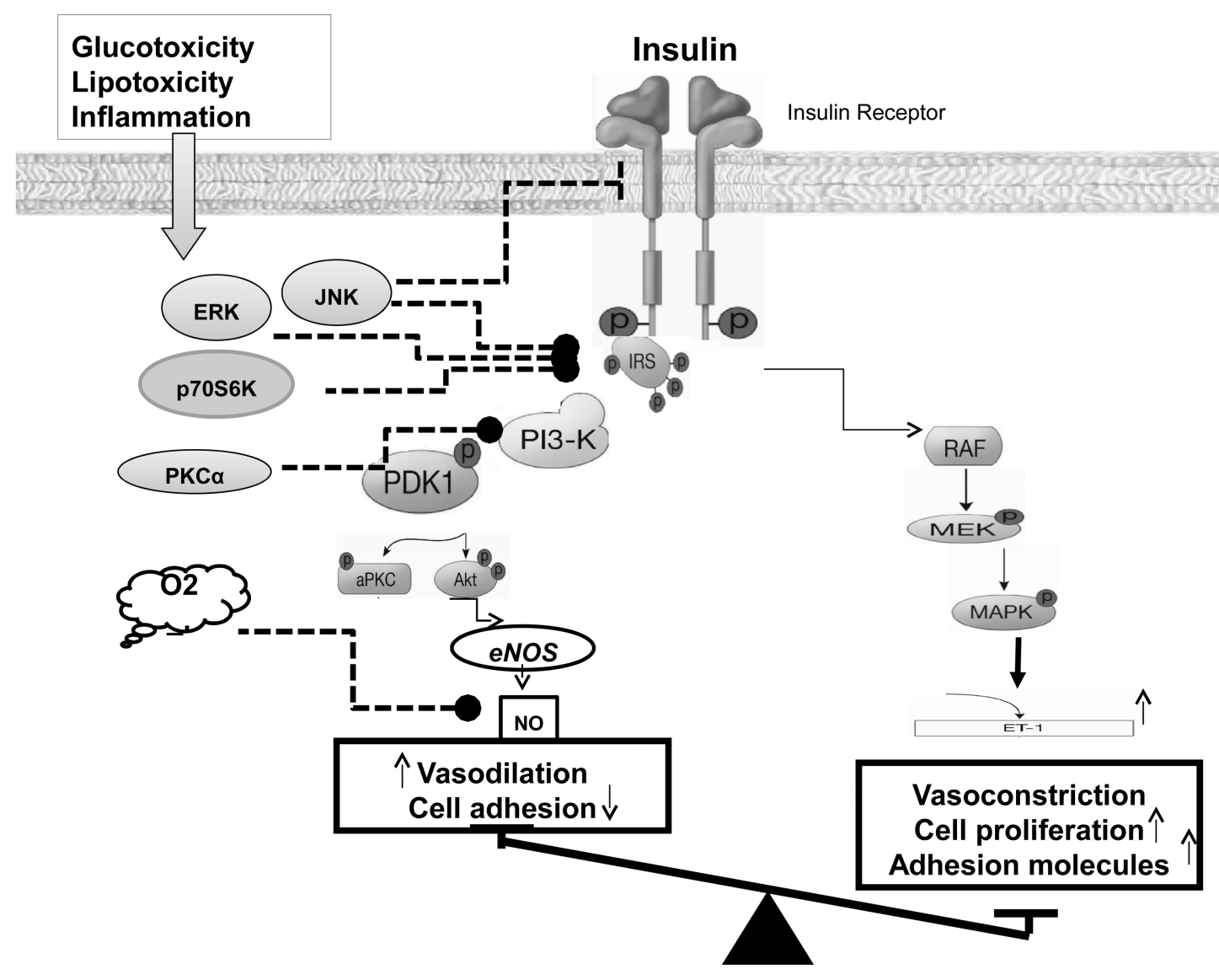

Figure 1. Pathway-specific impairment of insulin signaling pathway and endothelial dysfunction PI 3-kinase branch of insulin signaling regulates NO production and vasodilation in vascular endothelium. MAP-kinase branch of insulin signaling controls secretion of endothelin-1 (ET-1) and adhesion molecule expression in vascular endothelium. Glucotoxicity, lipotoxicity, and various cytokines activate signaling molecules that inhibit PI3K/Akt signaling. eNOS, endothelial nitric oxide synthase; IRS, insulin receptor substrate; MEK, MAPK kinase; PDK, phosphoinositide-dependent protein kinase; PKC, protein kinase C; IRS, insulin receptor substrate; ERK, extracellular signal-regulated kinase; JNK, C-Jun Nterminal kinase; p70S6K, p70 ribosomal S6 kinase; AP-1, activator protein-1; NO, nitric oxide; and ET-1, endothelin-1. 


\section{Correlation (Schmidt-Hunter) meta-analysis plot}

\section{Study}

\section{Correlation (Schmidt-Hunter) meta-analysis plot}

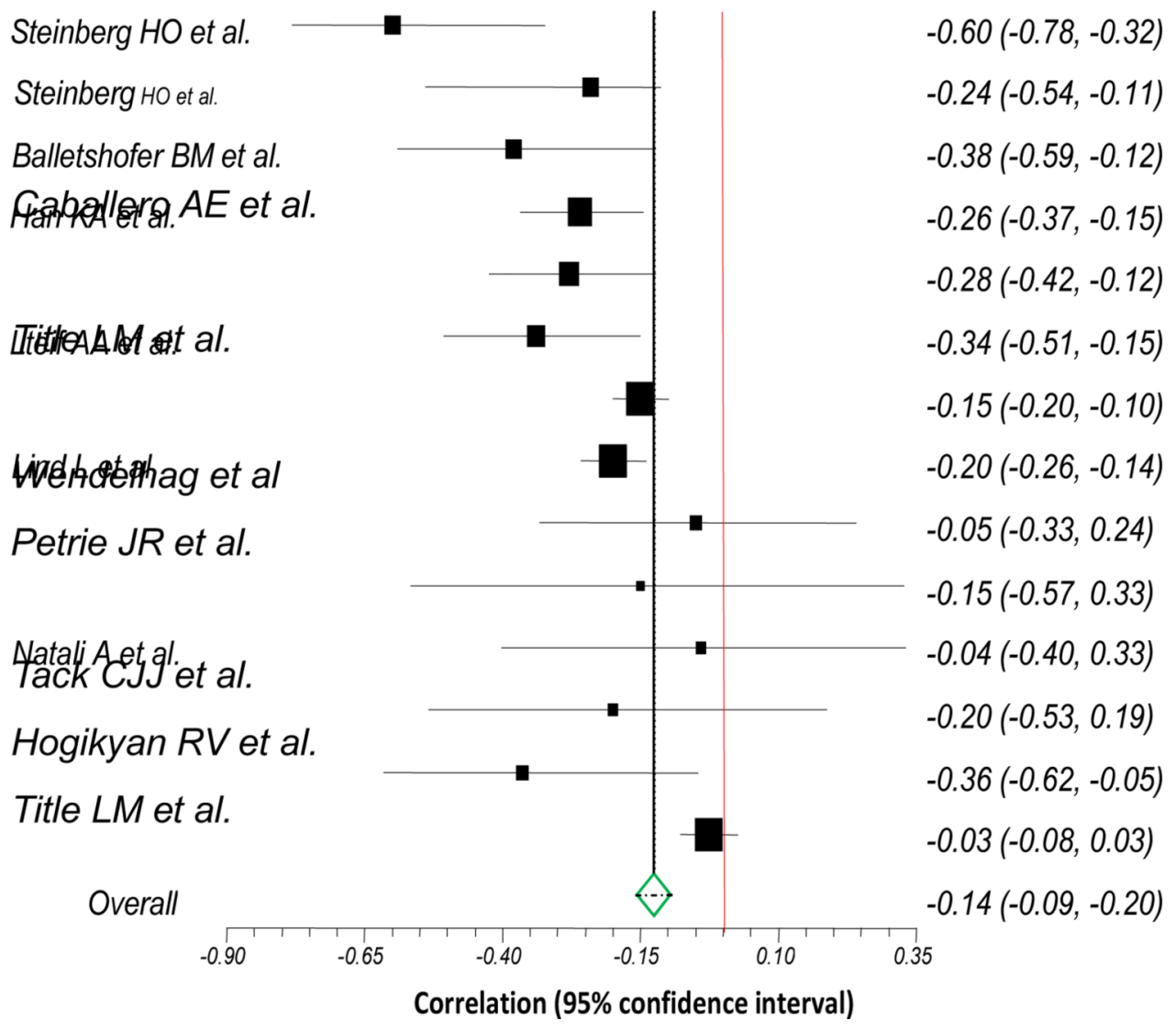

Figure 2. Correlation Meta-analysis

Univariate correlation coefficients between insulin sensitivity and endothelial function and corresponding $95 \%$ confidence intervals. 